\title{
Clinical impact of early minimal residual disease detection at day 15 in precursor B- childhood acute lymphoblastic leukemia: an Egyptian experience
}

Botheina Ahmed Thabet Farweez ${ }^{1 *} \mathbb{D}$, Nevine Ahmed Kassim, Mona Fathy Abdelfataah', Naglaa Mostafa Hassan², Doha Elsayed Ahmed Hassnien ${ }^{1}$ and Yasmin Nabil El-Sakhawy ${ }^{1}$

\begin{abstract}
Background: Chromosomal abnormalities in childhood acute lymphoblastic leukemia (ALL) are well-established prognostic markers and useful tools for minimal residual disease (MRD) assessment. This study aimed to stratify high-risk precursor B-childhood ALL (pre-B-ALL) patients according to standard prognostic factors (age and total leucocytic count), fluorescence in situ hybridization (FISH) analysis for these cytogenetic abnormalities [t (9;22) BCR/ $A B L, t(1 ; 19) T C F 3 / P B X 1$, and 11q23 MLL gene rearrangement], and MRD status at day 15 . Besides, we aimed to demonstrate the relation of these prognostic factors (standard and cytogenetic risk groups) to patients' outcome at day 15 of induction therapy as well as exploring the impact of early MRD assessment during remission induction compared to other prognostic factors together with the ability to tailor investigations as needed especially in places with limited health resources without compromising the outcome. Seventy-two newly-diagnosed Egyptian children with pre-B-ALL, aged 6 months to 15.5 years, registered from February 2016 to February 2018 were included. They were treated according to the modified Children's Oncology Group (COG) protocol. Patients were classified into (a) standard and high-risk groups according to standard prognostic factors. (b) Patients with the studied cytogenetic abnormalities and patients without the studied cytogenetic abnormalities. (c) Good outcome (negative MRD) and bad outcome (positive MRD) groups according to day 15 MRD status.

Results: The studied cytogenetic abnormalities were identified in $22.2 \%$ of patients, all of them were in the highrisk group, and 75\% of them had a bad outcome (positive MRD) at day 15 of induction therapy.

Conclusion: Patients with favorable presenting features (standard risk) and undetectable MRD after 2 weeks remission induction therapy would not be in need to advanced molecular studies, while these studies should be considered for patients with high-risk presenting features and high levels of MRD after 2 weeks remission induction therapy. Therefore, this could provide a cost-effective guideline in countries suffering from financial challenges without affecting the outcome
\end{abstract}

Keywords: Cytogenetic abnormalities, Day 15 MRD, Precursor B-childhood ALL, Prognostic factors

\footnotetext{
* Correspondence: dr_botheina@hotmail.com

${ }^{1}$ Clinical and Chemical Pathology Department, Hematology unit, Faculty of

Medicine, Ain Shams University, Cairo, Egypt

Full list of author information is available at the end of the article
}

\section{Springer Open}

( ) The Author(s). 2020 Open Access This article is licensed under a Creative Commons Attribution 4.0 International License, which permits use, sharing, adaptation, distribution and reproduction in any medium or format, as long as you give appropriate credit to the original author(s) and the source, provide a link to the Creative Commons licence, and indicate if changes were made. The images or other third party material in this article are included in the article's Creative Commons licence, unless indicated otherwise in a credit line to the material. If material is not included in the article's Creative Commons licence and your intended use is not permitted by statutory regulation or exceeds the permitted use, you will need to obtain permission directly from the copyright holder. To view a copy of this licence, visit http://creativecommons.org/licenses/by/4.0/. 


\section{Background}

The outcome of childhood acute lymphoblastic leukemia (ALL) has dramatically improved over the last 50 years with current cure rates approaching $90 \%$, and this is attributable to the introduction and gradual intensification of combination chemotherapy, with contemporary regimens involving the use of 7-8 drugs, along with improvement of prognostic factors [1].

However, with current therapeutic regimens, a proportion of children are likely to be over-treated while a proportion may benefit from more intensive therapy. Thus, it remains challenging to make this balance to achieve a cure with minimal chemotherapy to avoid unnecessary toxicities. This goal could be achievable by tailoring therapy to each patient's prognostic profile [2].

Several studies have shown that minimal residual disease (MRD) status, which signifies leukemic cells undetectable by morphologic examination of bone marrow smears, during the early stages of therapy, provides prognostic information independent of more classic prognostic markers such as presenting white blood cell count, age, cytogenetic analyses, and the immunophenotype. In many ALL protocols, days 8 and 15 of induction therapy are considered the first checkpoints to test the in vivo sensitivity of leukemia in the individual patient; thus, enabling risk-directed therapy [3].

Individual chromosomal abnormalities remain strong independent indicators of ALL outcomes, especially to show the risk of relapse [4]. Among these abnormalities, those with the most significant impact of risk stratification for treatment are $\mathrm{t}(9 ; 22)$ (q34; q11)/BCR-ABL1, 11q23(Mixed lineage leukemia) (MLL) gene rearrangements, and $t(1 ; 19)$ (q23; p13.3)/TCF3-PBX1 fusion [5, 6]. However, in countries with limited health resources and financial challenges, there is a great difficulty to perform all required investigations. This study aimed to stratify high-risk precursor Bchildhood ALL patients according to standard prognostic factors (age and total leucocytic count), fluorescence in situ hybridization (FISH) analysis for these cytogenetic abnormalities [t $(9 ; 22)$ BCR/ABL, $t(1 ; 19)$ TCF3/PBX1, and 11q23 MLL gene rearrangement] and MRD status at day 15. Also, we worked towards showing the relation of these prognostic factors (standard and cytogenetic risk groups) to patients' outcome at day 15 of induction therapy moreover assessing the impact of early MRD assessment during remission induction compared to other prognostic factors together with the ability to tailor investigations as needed especially in places with limited health resources without compromising the outcome.

\section{Methods}

\section{Patients}

From February 2016 to February 2018, seventy-two newly diagnosed Egyptian children with precursor B
ALL (pre-B-ALL) (6 months to 15.5 years old with a mean of $5.37+4.09$ years) were enrolled. The institutional review board approved the protocol, and the procedures respected the ethical standards in the Helsinki declaration of 1964. We obtained written informed consents from patients' guardians to use their samples in this study.

\section{Sampling}

Peripheral blood (PB) and bone marrow (BM) aspiration samples were collected under complete aseptic conditions into ethylene diamine tetra-acetic acid, potassium salt (K2-EDTA) vacutainer for complete blood count $(\mathrm{CBC})$ and immunophenotyping (IPT). For cytogenetic analysis $1 \mathrm{ml}$ of BM aspirate was collected into lithium heparin vacutainer, besides $1 \mathrm{ml} \mathrm{PB}$ in patients with $\mathrm{PB}$ blasts $>10 \%$. We collected samples with special emphasis on pre-analytical precaution guidelines.

\section{Diagnosis and MRD measurement}

We based diagnosis on standard morphologic, cytochemical, immunophenotypic, and genetic features of the leukemic cells [7]. At diagnosis, all patients were subjected to complete history taking; data about the clinical examination were obtained from patients' medical records, laboratory investigations including complete blood count using LH750 (Beckman Coulter, Electronics, Hialeah, FL, USA), an examination of Leishman's stained peripheral blood films, bone marrow aspiration and examination of Leishman's stained bone marrow smears, and cytochemical studies using myeloperoxidase stain. Immunophenotyping of bone marrow or peripheral blood samples using Navios Flow cytometer (Beckman Coulter, Electronics, Hialeah, FL, USA). Fluorescence in situ hybridization (FISH) analysis was performed according to Campbell [8], following practice cytogenetic guidelines 2007 and 2010, Quality Assurance Guidelines 2013 [9], and analyzed by at least two of the trained team of specialists using Cyto Vision Leica Microsystem using the following probes: Locus specific identifier (LSI) dual-color single fusion (SF) and/or double fusion (DF) BCR/ABL probe for $\mathrm{t}(9$; 22) (q34; q11) (Vysis), LSI DF TCF3/PBX1 probe for $t(1 ; 19)$ (q23; p13), and LSI Mixed Lineage Leukemia (MLL) Dual Color, Break Apart Rearrangement Probe designed to detect the $11 \mathrm{q} 23$ rearrangement associated with various translocations involving region 2 band 3 of chromosome 11.

Day 15 MRD status was determined by the morphological examination of Leishman's stained bone marrow smears, FISH for $\mathrm{t}(1 ; 19)$ (q23; p13) and MLL rearrangements and polymerase chain reaction $(\mathrm{PCR})$ analysis for $\mathrm{t}(9 ; 22)$ (q34; q11). 


\section{Cytogenetic analysis by FISH technique}

The culture conditions were optimized; blocking agent (N-Deacetyl-N-methylcolchicine) was added to the culture medium before harvest. Slides were prepared from material fixed in methanol-acetic acid. All probes were set up (according to manufacturer guidelines/Vysis) separately on different slides for each patient. Hybridization and detection of hybridization signals were performed according to the manufacturer's protocols. To maximize the likelihood of detecting a neoplastic clone, 200 interphase cells were evaluated for each case using the CytoVision Leica Microsystem to detect the target abnormalities. Images of FISH were captured through the program Mac Probe 4.4 of Power Gene System (Applied Imaging Corporation, USA). Thresholds and the confidence limit were established for all FISH probes and probe sets in the cytogenetic lab, where the variation of aberrant signal patterns was documented for a number of 10 normal and 20 abnormal samples for each probe to give the false positive/negative ranges and to check the intensity of the signals of the probes used. The cutoff for LSI dual-color SF and DF BCR/ABL probe for $\mathrm{t}(9 ; 22)(\mathrm{q} 34 ; \mathrm{q} 11)$ was $>10 \%$ and $>1.3 \%$ of examined cells, respectively. The cutoff for MLL dualcolor break apart rearrangements probe was $>6 \%$ of examined cells and for LSI DF TCF3/PBX1 was $>1.3 \%$ of examined cells. Interpretation of FISH probes was done according to manufacturer documentation. The limitations of the test were documented in the report.

\section{Risk stratification}

Risk stratification was based on clinical data and laboratory data [10]. Standard-risk ALL group involved patients with age 1-9.99 years and white blood cell count (WBC) count $<50 \times 10^{9} / \mathrm{L}$. The high-risk group involved patients with age $<1$ year or $\geq 10$ years and/or $\mathrm{WBC} \geq 50 \times 10^{9} / \mathrm{L}[11]$.

\section{The protocol of therapy (adopted from and under the supervision of Pediatric Hematology department clinicians)}

Standard-risk ALL patients were treated according to the Children's Oncology Group (COG) 1991 protocol [12] using a single delayed intensification (DI) arm. The COG 1961 protocol [13] was adopted for the treatment of high-risk ALL patients. The NCI high risk and rapid early responder (RER) $(<5 \%$ BM blast at day 15$)$ patients received the standard regimen of COG-1961 (standard arm of high-risk protocol, HRSA), while patients who were slow early responders (SER) (> 5\% BM blast at day 15) and patients with initial central nervous system (CNS) disease received the augmented regimen of COG1961 (augmented arm of high-risk protocol, HR-AA).
All three groups used dexamethasone as the sole steroid, single intrathecal therapy (IT), L-asparaginase (Escherichia coli) doses of $6000 \mathrm{IU} / \mathrm{m} 2$ with no highdose methotrexate (MTX), and monthly pulses of vincristine (VCR) and dexamethasone during maintenance phases. Standard risk therapy consisted of 3 drugs induction without anthracyclines; consolidation involved 6mercaptopurine, VCR with IT monotherapy, and one DI. High-risk standard arm therapy involved 4 drugs induction with anthracylines added and one DI. Both groups should have day 15 BM blasts < 5\% (RER). The high-risk augmented arm therapy involved 4 drugs induction, with anthracylines added, cranial irradiation during the consolidation phase, and escalating IV MTX followed by $E$. coli asparaginase at $15,000 \mathrm{IU} / \mathrm{m} 2$ with Capizzi regimen during the interim maintenance phase and double delayed intensification (DDI).

\section{Data management and analysis}

Data were analyzed using the SPSS software (Statistical Package for the Social Sciences, Version 20.0, SPSS Inc. Chicago, IL, USA). Quantitative data were expressed as mean \pm standard deviation (SD) and minimum and maximum values (range). Qualitative data were expressed as frequency and percentage.

Independent samples $t$ test of significance was used when comparing two means, and Fisher exact test was used to compare proportions between two qualitative variables.

- $P$ value: level of significance, $P>0.05$ : nonsignificant (NS), $P \leq 0.05$ : significant (S), and $P \leq 0.001$ : highly significant $(\mathrm{HS})$

\section{Results}

The baseline characteristics of the studied patients' group are shown in Table 1.

According to risk classification, we had 32 (44.4\%) patients in the standard risk and 40 (55.6\%) patients in the high-risk group. On comparing both groups, they showed a significant difference regarding BM blast percentage at day 15 (mean 2.0 vs.7.20, respectively) $(P=$ 0.007 ) and the outcome at day 15 where the majority of the high-risk group ( $60 \%$ of them) had a poor outcome in terms of no achievement of remission either morphological (SER) or molecular, while $87 \%$ of standard risk group had a good outcome $(P=0.005)$. However, there was no significant difference as regards other studied parameters. It was noted that all patients identified with the studied cytogenetic abnormalities at diagnosis were in the high-risk group.

Patients identified with the studied cytogenetic abnormalities at diagnosis were 16/72 (22.2\%) (Fig. 1); they were as follows: $4(5.6 \%)$ had $\mathrm{t}(9 ; 22) \mathrm{BCR} / \mathrm{ABL}, 8$ (11.1\%) had $\mathrm{t}(1 ; 19)$ TCF3/PBX1, and $4(5.6 \%)$ had 
Table 1 Baseline characteristics of studied patients at diagnosis

\begin{tabular}{|c|c|c|}
\hline Parameter & Number $n=(72)$ & $\%$ \\
\hline \multicolumn{3}{|l|}{ Sex } \\
\hline Male & 42 & $58.3 \%$ \\
\hline Female & 30 & $41.7 \%$ \\
\hline \multicolumn{3}{|l|}{ Clinical data } \\
\hline Hepatomegaly & 40 & $55.6 \%$ \\
\hline Splenomegaly & 36 & $50 \%$ \\
\hline Lymphadenopathy & 56 & $77.8 \%$ \\
\hline CNS infiltration & 8 & $11.1 \%$ \\
\hline Laboratory data & Range & Mean $( \pm$ SD) \\
\hline $\operatorname{TLC}\left(\times 10^{9} / \mathrm{L}\right)$ & $2.9-150$ & $47.59(34.91)$ \\
\hline $\mathrm{Hb}(\mathrm{gm} / \mathrm{dl})$ & $3.4-11.7$ & $7.69(1.78)$ \\
\hline Platelets $\left(\times 10^{9} / \mathrm{L}\right)$ & $12-132$ & $72.42(30.35)$ \\
\hline Peripheral blood blasts (\%) & $6-80$ & $32.17(23.83)$ \\
\hline Blasts in B.M (\%) & $36-98$ & $71.39(18.57)$ \\
\hline \multicolumn{3}{|c|}{$\begin{array}{l}\text { Immunophenotyping (n) (\%) } \\
\text { - CD19 (72/72) }(100 \%) \\
\text { - HLA-Dr (72/72) (100\%) } \\
\text { - CD10 (68/72) }(94.4 \%) \\
\text { - CD34 (66/72) }(91.6 \%) \\
\text { - CD20 (10/72) }(13.8 \%) \\
\text { - Aberrant expression (20/72) (27.7\%) } \\
\text { - Myeloid markers (8/72) (11.1\%) } \\
\text { - T cell marker (12/72) (16.6\%) }\end{array}$} \\
\hline \multicolumn{3}{|c|}{$\begin{array}{l}\text { Cytogenetics }(\boldsymbol{n}=\mathbf{1 6 / 7 2})(\mathbf{2 2 . 2} \%) \\
-\mathrm{t}(9 ; 22)(\mathrm{BCR} / \mathrm{ABL})(4 / 72)(5.6 \%) \\
\text { - t }(1 ; 19)(\mathrm{TCF} 3 / \mathrm{PBX} 1)(8 / 72)(11.1 \%) \\
-11 \mathrm{q} 23 \text { rearrangement }(4 / 72)(5.6 \%)\end{array}$} \\
\hline
\end{tabular}

$T L C$ total leukocytic count, $H b$ hemoglobin, IPT immunophenotyping, $P B$ peripheral blood, $B M$ bone marrow 11q23 rearrangement (Table 2) (Figs. 2, 3, 4 and 5). On comparing patients identified with the studied cytogenetic abnormalities to the group of patients without these abnormalities, there were significant differences between both groups regarding risk classification, TLC and PLTs at diagnosis, BM blast cells percentage at day 15 , and outcome (Table 3).

According to day 15 MRD status [14], patients were classified into good and bad outcome groups where good outcome meant both morphologically remitted (BM blasts $<5 \%$ ) and molecularly remitted (MRD negative), while bad outcome meant no achievement of remission either morphologically (BM blasts $>5 \%$ ) or molecularly (MRD positive) (Fig. 6). Comparison between both groups is shown in Table 4.

\section{Characteristics of good outcome patients at day 15}

Two of $t(9 ; 22)$ BCR/ABL positive patients had a good outcome. Their ages were 3.5 and 5.0 years, they had no CNS infiltration, at diagnosis TLC was $\left(51.4 \times 10^{9} / \mathrm{L}\right.$ and $\left.55.0 \times 10^{9} / \mathrm{L}\right)$, and PLTs was $\left(70 \times 10^{9} / \mathrm{L}\right.$ and $\left.55 \times 10^{9} / \mathrm{L}\right)$ compared to the other two patients who had a bad outcome. Their ages were 11 and 10 years old, both had CNS infiltration, at diagnosis their TLC was higher $(120 \times$ $10^{9} / \mathrm{L}$ and $\left.118 \times 10^{9} / \mathrm{L}\right)$, and PLTs were lower $\left(23 \times 10^{9} / \mathrm{L}\right.$ and $\left.36 \times 10^{9} / \mathrm{L}\right)$.

Two of $t(1 ; 19)$ TCF3/PBX1 positive patients had a good outcome. They had the lowest TLC at diagnosis $\left(42.5 \times 10^{9} / \mathrm{L}\right.$ and $\left.52.0 \times 10^{9} / \mathrm{L}\right)$ compared to the other 6 patients, one was 9 months and the other was 5 years old.

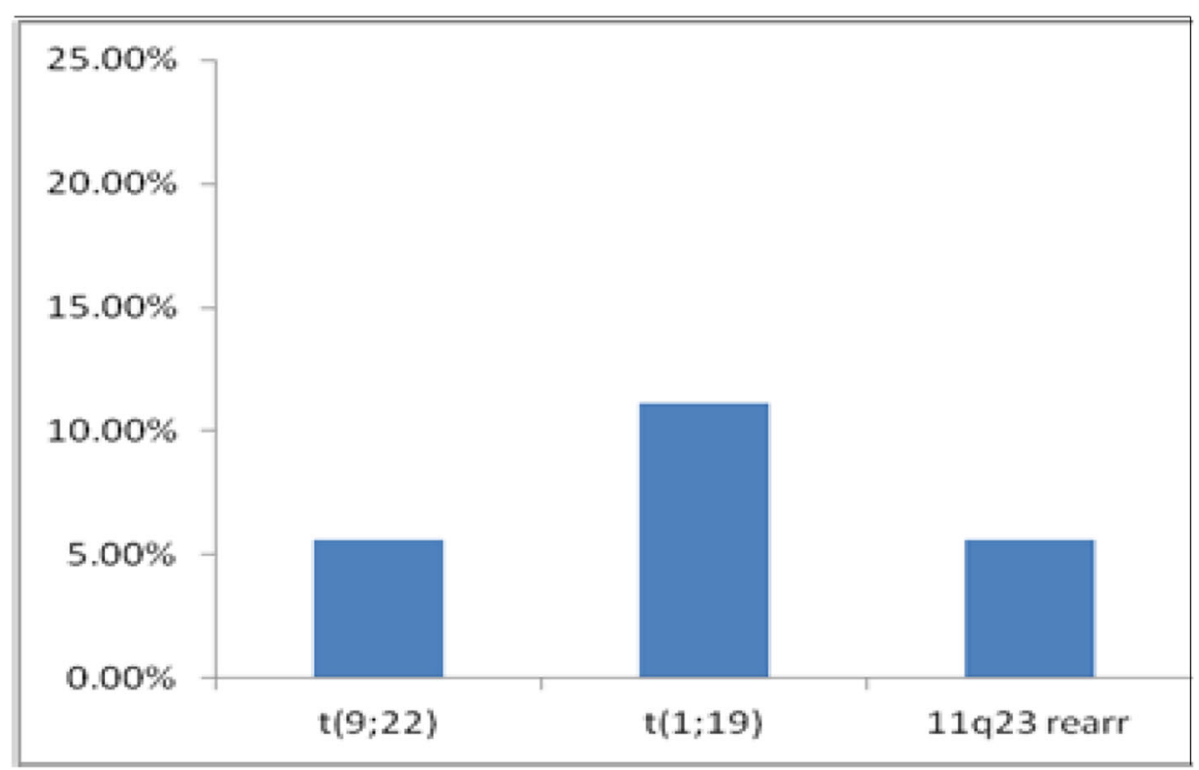

Fig. 1 Percentage of each cytogenetic abnormality 
Table 2 Clinical and laboratory characteristics of the studied cytogenetic groups

\begin{tabular}{|c|c|c|c|}
\hline Parameter & $\mathrm{t}(9 ; 22) \boldsymbol{n}=(4)$ & $\mathrm{t}(1 ; 19) \boldsymbol{n}=(8)$ & $11 \mathrm{q} 23$ rearrangement $\boldsymbol{n}=(4)$ \\
\hline \multicolumn{4}{|l|}{ Age } \\
\hline$<1$ year- & 0 & 4 & 2 \\
\hline $1-9$ years & 2 & 4 & 2 \\
\hline$\geq 10$ years & 2 & 0 & 0 \\
\hline \multicolumn{4}{|l|}{ Sex } \\
\hline Male & 4 & 6 & 2 \\
\hline Female & 0 & 2 & 2 \\
\hline \multicolumn{4}{|l|}{ Clinical data } \\
\hline Hepatomegaly & 4 & 8 & 2 \\
\hline Splenomegaly & 4 & 4 & 4 \\
\hline Lymphadenopathy & 4 & 8 & 0 \\
\hline CNS infiltration & 2 & 0 & 2 \\
\hline Laboratory data (at diagnosis) & Mean ( \pm SD) & Mean ( \pm SD) & Mean $( \pm S D)$ \\
\hline $\mathrm{TLC}\left(\times 10^{9} / \mathrm{L}\right)$ & $86.1 \pm 48.9$ & $87.4 \pm 44.81$ & $89.25 \pm 17.04$ \\
\hline $\mathrm{Hb}(\mathrm{gm} / \mathrm{dl})$ & $6.7 \pm 1.1$ & $7.93 \pm 2.12$ & $9.05 \pm 1.63$ \\
\hline Platelets $\left(\times 10^{9} / \mathrm{L}\right)$ & $46.5 \pm 7.7$ & $49.75 \pm 34.07$ & $55.50 \pm 13.44$ \\
\hline Peripheral blood blasts (\%) & $29.0 \pm 4.2$ & $28.0 \pm 28.93$ & $18.50 \pm 3.54$ \\
\hline Blasts in B.M (\%) & $68.5 \pm 3.5$ & $58.5 \pm 18.27$ & $63.5 \pm 38.89$ \\
\hline Laboratory data (at day 15 of induction) & Mean $( \pm S D)$ & Mean ( \pm SD) & Mean $( \pm \mathrm{SD})$ \\
\hline $\operatorname{TLC}\left(\times 10^{9} / \mathrm{L}\right)$ & $1.8 \pm 1.4$ & $1.25 \pm 0.45$ & $1.80 \pm 1.41$ \\
\hline $\mathrm{Hb}(\mathrm{gm} / \mathrm{dl})$ & $7.7 \pm 0.4$ & $7.8 \pm 1.14$ & $7.85 \pm 0.49$ \\
\hline Platelets $\left(\times 10^{9} / L\right)$ & $110.5 \pm 27.6$ & $51.0 \pm 29.46$ & $69.5 \pm 23.33$ \\
\hline Blasts in B.M (\%) & $12.5 \pm 13.4$ & $10.25 \pm 7.5$ & $13.50 \pm 7.78$ \\
\hline \multicolumn{4}{|l|}{ MRD status at day 15} \\
\hline Good outcome & 2 & 2 & 0 \\
\hline Bad outcome & 2 & 6 & 4 \\
\hline
\end{tabular}

$T L C$ total leukocytic count, $H b$ hemoglobin, $P B$ peripheral blood, $B M$ bone marrow, $S D$ standard deviation, $n$ number

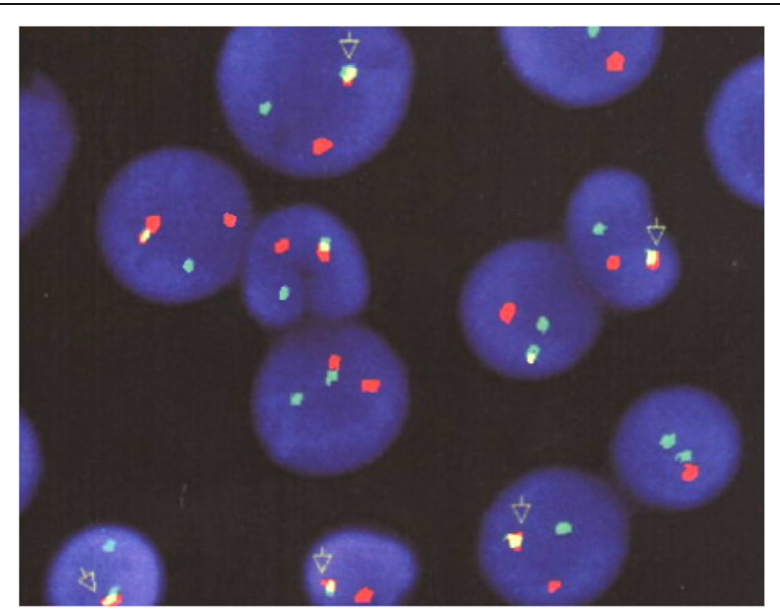

Fig. 2 An interphase FISH analysis applied at diagnosis using LSI single fusion (SF) probe BCR/ABL positive for $\mathrm{t}(9 ; 22)$ (q34;q11), I yellow signal represents the typical fusion signal of translocation in addition to one green signal (BCR) and one red signal $(A B L)$
None of the patients' group with 11q23 rearrangement had a good outcome. One patient had morphological remission but was not molecularly remitted (11q23 rearrangement still positive by FISH analysis), so he was also considered to have a bad outcome. His age was 3 years and had TLC of $72.2 \times 10^{9} / \mathrm{L}$.

\section{Discussion}

Acute lymphoblastic leukemia (ALL) is the most common cancer diagnosed in children constituting about $30 \%$ of cancers diagnosed in children younger than 15 years of age, with peak prevalence during 2-5 years of life [15]. Risk stratification allows the physician to determine the most appropriate initial treatment regimen as well as when to consider allogeneic stem cell transplantation [16].

Age and white blood cell count at the time of diagnosis have been used to risk-stratify patients [10]. Moreover, TLC at time of diagnosis is one of the most important determinates of MRD, remission induction, 


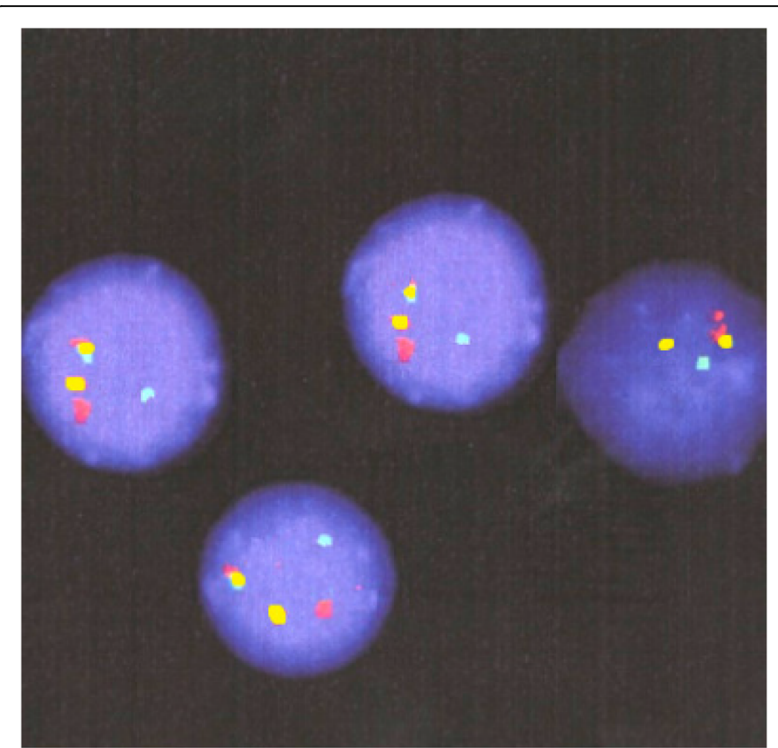

Fig. 3 An interphase FISH analysis applied for follow-up using LSI double fusion (DF) probe BCR/ABL positive for $\mathrm{t}(9 ; 22)$ (q34;q11), 2 yellow signal represents the typical fusion signal of translocation in addition to one green signal $(B C R)$ and one red signal (ABL)

and duration [17]. Patients with higher counts TLC $>50$ $\times 10^{9} / \mathrm{L}$ have a high risk for treatment failure than the lower counts [18]. Increasing age $>10$ years and/or TLC $>50 \times 10^{9} / \mathrm{L}$ portends a worsening prognosis, and patients are categorized as high-risk group [19].

Although clinical factors play an important role in guiding therapy, cytogenetic changes have a significant role in risk determination. From the cytogenetic aberrations with the greatest impact on prognosis and treatment is the presence of the Philadelphia chromosome $t$ $(9 ; 22), \mathrm{t}(1 ; 19)$, and MLL rearrangements [20].

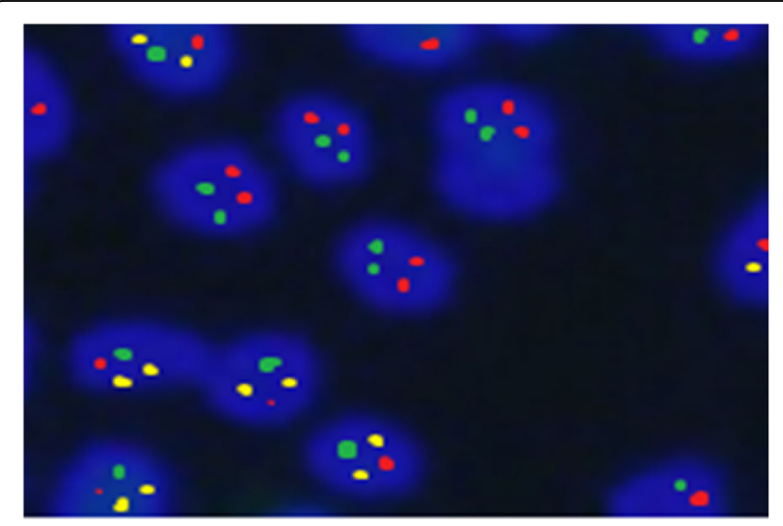

Fig. 4 An interphase FISH analysis applied at diagnosis using LSI DF TCF3/PBX1 Dual Color Probe positive for $\mathrm{t}(1 ; 19)$ (q23;p13), 2 yellow signals (juxtaposed red and green) represent the typical fusion signal of translocation in addition to one green signal and one red signal

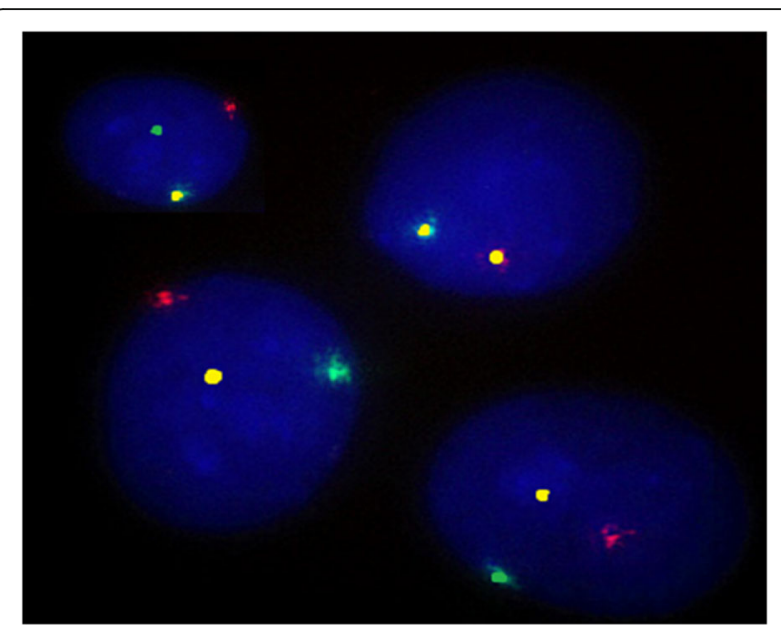

Fig. 5 An interphase FISH analysis applied at diagnosis using LSI break apart MLL probe positive for 11 q23 rearrangements, 1 yellow signal (juxtaposed red and green) represents the normal copy of MLL gene in addition to one green signal and one red signal represent the rearranged copy of MLL (11q23 rearrangement)

In our study, the group of patients identified with the studied cytogenetic abnormalities at diagnosis had higher mean TLC than patients without these abnormalities (most of them had TLC $\geq 50 \times 10^{9} / \mathrm{L}$ ), and so they were categorized in the high-risk group. These results were in agreement with Al-Kzayer et al. [21] in their group of patients with $t(9 ; 22)$ and $11 q 23$ rearrangement. Also, Jeha et al. stated that patients with $\mathrm{t}(1 ; 19)$ were associated with higher TLC [22]. In contrast, Kager et al. reported a lower mean (TLC $<50 \times 10^{9} / \mathrm{L}$ ) among patients with $t(1 ; 19)[5]$, and Schultz et al. reported that their patients with $11 \mathrm{q} 23$ rearrangement did not meet the criteria of high-risk group with the mean of TLC $<50 \times 109 / \mathrm{L}[14]$.

Besides disease characteristics at diagnosis, it has long been recognized that response to initial therapy predicts outcome. Historically, treatment response was evaluated morphologically. Recently, it has become standard practice to evaluate patients for minimal residual disease (MRD) using molecular techniques such as flow cytometry, FISH, and PCR [23]. The ultimate goal of MRD assays is to guide therapeutic decisions by distinguishing patients in whom therapy must be continued or intensified to minimize the likelihood of clinical relapse [24].

In our cohort, MRD study of patients at day 15 of induction therapy showed that $61 \%$ had a good outcome (MRD negative) with the majority of them being in the age group 1-9 years, while the majority of a bad outcome (MRD positive) were in the age group > 10 years. This was in agreement with Harvey et al. [25] who reported that most of his patients' group of $>10$ years had a bad outcome with positive MRD at the end of induction. Cooper and Brown explained that the higher rate 
Table 3 Comparative analysis between patients' groups with and without studied cytogenetic abnormalities regarding different parameters

\begin{tabular}{|c|c|c|c|c|c|c|c|c|c|}
\hline \multirow[t]{3}{*}{ Parameters } & & \multicolumn{6}{|c|}{ Cytogenetic abnormalities } & \multicolumn{2}{|c|}{$\begin{array}{l}\text { Fisher exact } \\
\text { test }\end{array}$} \\
\hline & & \multicolumn{3}{|c|}{$\begin{array}{l}\text { Patients without the studied cytogenetic } \\
\text { abnormalities (56) }\end{array}$} & \multicolumn{3}{|c|}{$\begin{array}{l}\text { Patients with the studied cytogenetic } \\
\text { abnormalities (16) }\end{array}$} & \multirow[t]{2}{*}{$P$ value } & \multirow[t]{2}{*}{ Sig } \\
\hline & & $N$ & & $\%$ & & & $\%$ & & \\
\hline \multirow[t]{3}{*}{ Age (years) } & $<1$ & 4 & $7.1 \%$ & & 4 & $25.0 \%$ & & 0.335 & NS \\
\hline & $1-9$ & 38 & $67.9 \%$ & & 8 & $50.0 \%$ & & & \\
\hline & $>10$ & 14 & $25.0 \%$ & & 4 & $25.0 \%$ & & & \\
\hline \multirow[t]{2}{*}{ Sex } & Male & 30 & $53.6 \%$ & & 12 & $75.0 \%$ & & 0.424 & NS \\
\hline & Female & 26 & $46.4 \%$ & & 4 & $25.0 \%$ & & & \\
\hline \multirow[t]{2}{*}{ Hepatomegaly } & Absent & 30 & $53.6 \%$ & & 2 & $12.5 \%$ & & 0.053 & NS \\
\hline & Present & 26 & $46.4 \%$ & & 14 & $87.5 \%$ & & & \\
\hline \multirow[t]{2}{*}{ Splenomegaly } & Absent & 32 & $57.1 \%$ & & 4 & $25.0 \%$ & & 0.228 & NS \\
\hline & Present & 24 & $42.9 \%$ & & 12 & $75.0 \%$ & & & \\
\hline \multirow[t]{2}{*}{ Lymphadenopathy } & Absent & 12 & $21.4 \%$ & & 4 & $25.0 \%$ & & 1.000 & NS \\
\hline & Present & 44 & $78.6 \%$ & & 12 & $75.0 \%$ & & & \\
\hline \multirow[t]{2}{*}{ CNS infiltration } & Absent & 52 & $92.9 \%$ & & 12 & $75.0 \%$ & & 0.207 & NS \\
\hline & Present & 4 & $7.1 \%$ & & 4 & $25.0 \%$ & & & \\
\hline \multirow[t]{2}{*}{ Aberrant expression in (IPT) } & Negative & 40 & $71.4 \%$ & & 12 & $75.0 \%$ & & 1 & NS \\
\hline & Positive & 16 & $28.5 \%$ & & 4 & $25.0 \%$ & & & \\
\hline \multirow[t]{2}{*}{ Risk classification } & Standard risk & 32 & $57.2 \%$ & & 0 & $0 \%$ & & 0.009 & $\mathrm{~S}$ \\
\hline & High risk & 24 & $42.8 \%$ & & 16 & $100 \%$ & & & \\
\hline \multirow[t]{2}{*}{ Outcome } & Good & 40 & $71.4 \%$ & & 4 & $25.0 \%$ & & $<0.001$ & $\mathrm{~S}$ \\
\hline & Bad & 16 & $28.5 \%$ & & 12 & $75.0 \%$ & & & \\
\hline \multicolumn{10}{|l|}{ Laboratory parameters } \\
\hline \multirow[t]{2}{*}{ Parameters } & & & & & & & & $t$ test & \\
\hline & & Mean & SD & & Mean & SD & & $P$ value & Sig \\
\hline $\mathrm{Hb}(\mathrm{gm} / \mathrm{dL})$ & & 7.63 & 1.91 & & 7.90 & 1.81 & & 0.722 & NS \\
\hline $\mathrm{TLC}\left(\times 10^{9} / \mathrm{L}\right)$ & & 36.18 & 25.48 & & 87.54 & 35.29 & & $<0.001$ & $S$ \\
\hline Platelets $\left(\times 10^{9} / \mathrm{L}\right)$ & & 78.71 & 29.46 & & 50.38 & 23.32 & & 0.017 & $S$ \\
\hline PB blasts (\%) & & 34.68 & 24.62 & & 23.38 & 19.68 & & 0.198 & NS \\
\hline BM blasts (\%) & & 74.00 & 17.80 & & 62.25 & 19.51 & & 0.116 & NS \\
\hline BM blasts at day $15(\%)$ & & 2.96 & 4.09 & & 11.63 & 7.80 & & 0.016 & $\mathrm{~S}$ \\
\hline
\end{tabular}

No./n number, NS non-significant, Sig significance. $P \geq 0.05=\mathrm{NS} ; P<0.05=\mathrm{S} ; P<0.01=\mathrm{HS} ; S D$ standard deviation, $T L C$ total leukocytic count, $H b$ hemoglobin, IPT immunophenotyping, $P B$ peripheral blood, $B M$ bone marrow

of treatment-related morbidity and mortality are particularly secondary to infection, osteonecrosis, and thrombosis in this age group [26].

A significant association between the presence of the studied cytogenetic aberrations and MRD results at day 15 was found where $75 \%$ of patients with the studied cytogenetic abnormalities had positive MRD results at day 15 of induction therapy. Juárez-Velázquez et al. explained the bad outcome associated with the studied cytogenetic abnormalities in childhood B-ALL that these cytogenetic abnormalities influence the aggressive behavior of leukemic cells and resist the response to treatment by altering signaling pathways and gene expression patterns in the leukemic blasts; these genes lead to incomplete remission and MRD positivity [27].

Two of our patients with BCR/ABL did not achieve remission despite receiving tyrosine kinase inhibitors (TKI) (Imatinib) in induction. Schultz et al. reported that mostly these patients had resistance to TKI due to mutations in the nucleotide sequence of the ABL kinase domain encoding the ATP-binding [14]. Additional mechanisms leading to TKI resistance include gene 


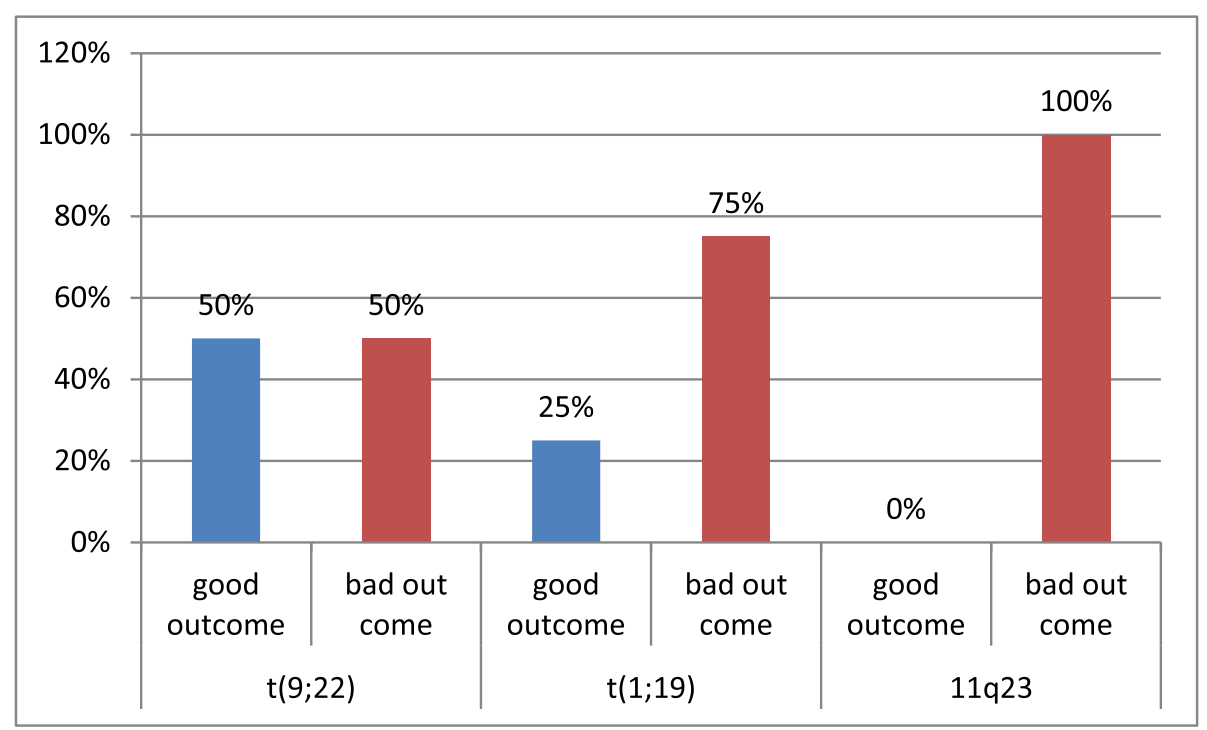

Fig. 6 The outcome at day 15 in each cytogenetic abnormality group

amplification of BCR-ABL and overexpression of the protein which plays a role in leukemic transformation by BCR-ABL in positive BCR/ABL ALL [28].

Moreover, six patients out of our eight patients with $t$ (1; 19) had a bad outcome (positive MRD) at day 15 . This was in alignment with Harvey et al. who reported that $80 \%$ of their patients with $\mathrm{t}(1 ; 19)$ had a bad outcome [25]. Shiozawa et al. explained that this bad outcome is due to treatment resistance which may be due to the presence of Mer-Tyrosine Kinase (Mer-TK), a receptor of tyrosine kinase which is overexpressed in $t$ ( 1 ; 19) and has a role in oncogenesis. This receptor is activated by GAS6 (growth arrest-specific 6) produced in bone marrow by mesenchymal cells causing the blast cells to be resistant to chemotherapy. So GAS6-MerTK interaction might be an important target for directed therapy in $t(1 ; 19)$ [29]. However, Moorman et al. reported $88 \%$ of his patients with $t(1 ; 19)$ had a good outcome with negative MRD due to high intensive therapy which improved their outcome [4]. Likewise, Pui et al. [30] found that patients with $t(1 ; 19) /(T C F 3-P B X 1)$ ALL had an intermediate outcome in terms of event-free survival (89.3\%) because of their increased risk of isolated CNS relapse, which intensified triple intrathecal therapy resulted in overall survival of $100 \%$ among these patients.

Patients with 11q23 rearrangement in our study had a bad outcome (positive MRD), three of them did not achieve morphological or molecular remission, and one patient was morphologically remitted but not molecularly remitted by FISH; this highlights the importance of molecular study for follow-up of patients. This result matched with Harvey et al. who reported that their patients with $11 \mathrm{q} 23$ rearrangement had a bad outcome
[25]. Woo et al. [31] explained that the poor response of $11 \mathrm{q} 23$ rearrangement (MLL) gene during the induction therapy may be due to overexpression of Fms-like tyrosine kinase 3(FLT3) oncogene and Homeobox (HOX) genes in association with $11 \mathrm{q} 23$ rearrangement; these genes cause chemotherapeutic resistance. Besides, these patients have a high risk of treatment-related mortality, and thus induction should include 1-week prophase of single-agent steroid to "debulk" the initial leukemic burden before initiation of multi-agent chemotherapy [32] This was also proven by Tamai and Inokuchi who reported that $80 \%$ of their patients achieved remission with new molecular therapeutic drugs of anti FLT3 which improved the outcome of patients with 11q23 rearrangement [33].

Thus, patients with positive MRD at day 15 of induction require intensification therapy and addition of specific drugs according to their cytogenetic abnormality present and are later offered a bone marrow transplant. While patients with negative MRD at day 15 of induction may be candidates for less intensive treatment regimens, thus avoiding unnecessary toxic effects [30]. Several published data on MRD assessment in pediatric ALL have shown a strong correlation between MRD response and outcome as well as the prognostic value of MRD reappearance for hematologic relapse. MRD has also been considered as a quantitative and objective extension of established endpoints of hematologic remission and relapse more than a substitute for pretherapeutic risk factors [34].

It was noticeable that all patients with the studied cytogenetic abnormalities were in the high-risk group of COG risk stratification approach, which intensifies 
Table 4 MRD study of all patients on day 15 regarding studied parameters

\begin{tabular}{|c|c|c|c|c|c|c|c|}
\hline \multirow[t]{3}{*}{ Parameters } & & \multicolumn{4}{|c|}{ MRD result (Outcome at day 15 ) } & \multicolumn{2}{|c|}{ Fisher exact test } \\
\hline & & \multicolumn{2}{|c|}{$\begin{array}{l}\text { Good outcome, negative MRD } \\
\qquad(n=44) 61.1 \%\end{array}$} & \multicolumn{2}{|c|}{$\begin{array}{l}\text { Bad outcome, positive MRD } \\
\qquad(n=28) 38.8 \%\end{array}$} & \multirow[t]{2}{*}{$P$ value } & \multirow[t]{2}{*}{ Sig. } \\
\hline & & $N$ & $\%$ & $N$ & $\%$ & & \\
\hline \multirow[t]{2}{*}{ Studied cytogenetics at diagnosis } & Positive & 4 & $8.1 \%$ & 12 & $42.8 \%$ & $<0.001$ & $\mathrm{~S}$ \\
\hline & Negative & 40 & $90.9 \%$ & 16 & $57.2 \%$ & & \\
\hline \multirow[t]{2}{*}{ Risk classification } & High risk & 16 & $36.4 \%$ & 24 & $85.7 \%$ & $<0.001$ & $\mathrm{~S}$ \\
\hline & Standard risk & 28 & $63.6 \%$ & 4 & $14.3 \%$ & & \\
\hline \multirow[t]{3}{*}{ Age } & $<1$ & 2 & $4.5 \%$ & 6 & $21.4 \%$ & 0.036 & $\mathrm{~S}$ \\
\hline & $1-9$ & 40 & $91.0 \%$ & 6 & $21.4 \%$ & & \\
\hline & $>10$ & 2 & $4.5 \%$ & 16 & $57.2 \%$ & & \\
\hline \multirow[t]{2}{*}{ Sex } & Male & 16 & $36.4 \%$ & 18 & $64.2 \%$ & 0.104 & NS \\
\hline & Female & 28 & $63.6 \%$ & 10 & $35.8 \%$ & & \\
\hline \multirow[t]{2}{*}{ Hepatomegaly } & Absent & 20 & $45.4 \%$ & 12 & $42.8 \%$ & 0.257 & NS \\
\hline & Present & 24 & $54.5 \%$ & 16 & $57.2 \%$ & & \\
\hline \multirow[t]{2}{*}{ Splenomegaly } & Absent & 22 & $50.0 \%$ & 14 & $50.0 \%$ & 0.228 & NS \\
\hline & Present & 22 & $50.0 \%$ & 14 & $50.0 \%$ & & \\
\hline \multirow[t]{2}{*}{ Lymphadenopathy } & Absent & 4 & $8.1 \%$ & 12 & $42.8 \%$ & 1.000 & NS \\
\hline & Present & 40 & $90.9 \%$ & 16 & $57.2 \%$ & & \\
\hline \multirow[t]{2}{*}{ CNS infiltration } & Absent & 42 & $95.5 \%$ & 22 & $78.6 \%$ & 0.207 & NS \\
\hline & Present & 2 & $4.5 \%$ & 6 & $21.4 \%$ & & \\
\hline \multicolumn{8}{|c|}{ Laboratory parameters } \\
\hline \multirow[t]{2}{*}{ Parameters } & & & & & & $t$ test & \\
\hline & & Mean & SD & Mean & SD & $P$ value & Sig \\
\hline $\mathrm{Hb}(\mathrm{gm} / \mathrm{dL})$ & & 8.32 & 1.44 & 7.55 & 0.91 & 0.178 & NS \\
\hline $\operatorname{TLC}\left(\times 10^{9} / \mathrm{L}\right)$ & & 1.79 & 0.76 & 1.13 & 0.51 & 0.027 & $S$ \\
\hline Platelets $\left(\times 10^{9} / \mathrm{L}\right)$ & & 102.32 & 56.74 & 61.75 & 23.12 & 0.014 & $\mathrm{~s}$ \\
\hline BM blasts (\%) & & 1.93 & 0.86 & 15.25 & 5.6 & $<0.001$ & $\mathrm{~S}$ \\
\hline
\end{tabular}

$N$ number, NS non-significant, $S$ significance. $P \geq 0.05=\mathrm{NS} ; P<0.05=\mathrm{S} ; P<0.01=\mathrm{HS}$; SD standard deviation, $T L C$ total leukocytic count, $H b$ hemoglobin, $B M$ bone marrow

treatment in patients with a high risk of relapse and reduces toxicity on those with a greater probability of cure (standard risk). Thus, based on the findings of this study and those reported in the literature $[35,36]$, we would recommend that patients with favorable presenting features (standard risk group) and undetectable MRD after 2 weeks remission induction therapy (morphologically and by flow cytometry) would not be in need to advanced molecular studies, while these approaches should be considered for patients with high risk presenting features and high levels of MRD after 2 weeks remission induction therapy. Therefore, this could provide a costeffective guideline in countries suffering from financial challenges without affecting the outcome. The high-risk patient from the start is molecularly evaluated and monitored, while the standard-risk patient is monitored, and early at day 15 of induction if the response is not what was anticipated, molecular studies should be done to investigate the unfavorable outcome and if in need for individualized therapy. Therefore, risk stratification continues to be the mainstay for initial therapy and investigation guidance for ALL patients.

\section{Conclusion}

We are aware of the limitations of our study being a singlecenter study, the small number of participants, and no longer follow-up period, which may be inadequate to determine and explain potentially unique influences on treatment outcomes tailored to genetic and environmental influences in a region. Despite these limitations, our study tries to apply an appropriate application of resources and to be useful in the design of future, increasingly personalized investigation protocols and still highlight the importance of early MRD assessment. 


\section{Abbreviations}

ALL: Acute lymphoblastic leukemia; BM: Bone marrow; CBC: Complete blood count; CD: Cluster of differentiation; CNS: Central nervous system; COG: Children's Oncology Group; DDI: Double delayed intensification; DF: Double fusion; DI: Delayed intensification; FISH: Fluorescence in situ hybridization; FLT3: Fms-like tyrosine kinase 3; Hb: Hemoglobin; HOX: Homeobox genes; HR-AA: Augmented arm of high-risk protocol; HRSA: Standard arm of high-risk protocol; IPT: Immunophenotype, immunophenotyping; IT: Intrathecal therapy; K2-EDTA: Ethylene diamine tetra-acetic acid, potassium salt; LSI: Locus specific identifier; MLL: Mixed lineage leukemia gene; MRD: Minimal residual disease; MTX: Methotrexate; PB: Peripheral blood; PLTs: Platelet count; PCR: Polymerase chain reaction; RER: Rapid early responders; SD: Standard deviation; SER: Slow early responders; SF: Single fusion; SPSS: Statistical Package for the Social Sciences; TKI: Tyrosine kinase inhibitor; TLC: Total leucocytic count; VCR: Vincristine; WBCs: White blood cells count

\section{Acknowledgements}

Not applicable.

\section{Authors' contributions}

NK: Study concept and supervision, protocol design, technical support in practical part and critical revision of the manuscript for intellectual content. BF: Helps in protocol design, study supervision, analysis of data, preparing the initial draft of the manuscript and the final revision. MA: Helps in analysis of data, study supervision and the final revision. YE: Helps in protocol design, study supervision, analysis of data, preparing the initial draft of the manuscript, and the final revision. NH: Helps in collecting data, its analysis, and the final revision. DH: Helps in protocol design; collecting data; analysis of data; preparing the initial draft of the manuscript, material support, and final revision.

Finally, all authors have read and approved the manuscript.

\section{Funding}

Not applicable.

\section{Availability of data and materials}

All data generated or analyzed during this study are included in this published article, and its supplementary information files are available from the corresponding author on reasonable request.

\section{Ethics approval and consent to participate}

The protocol was approved by the institutional review boards of Ain-Shams University Hospitals, Faculty of medicine and Hematology/Oncology unit of National Cancer Institute (Reference number FMASU FWA 00006444), and the procedures respected the ethical standards in Helsinki declaration of 1964. Written informed consents were obtained from patients' guardians to use their samples in this study.

\section{Consent for publication}

Not applicable

\section{Competing interests}

The authors declare that they have no competing interests.

\section{Author details}

${ }^{1}$ Clinical and Chemical Pathology Department, Hematology unit, Faculty of Medicine, Ain Shams University, Cairo, Egypt. ${ }^{2}$ Clinical and Chemical Pathology Department, National Cancer Institute, Cairo University, Cairo, Egypt.

Received: 7 November 2019 Accepted: 30 April 2020 Published online: 08 July 2020

\section{References:}

1. Irving J, Jesson J, Virgo P, Case M, Minto L, Eyre L et al (2009) Establishment and validation of a standard protocol for the detection of minimal residual disease in $\mathrm{B}$ lineage childhood acute lymphoblastic leukemia by flow cytometry in a multi-centre setting. Haematologica. 94:870-874

2. Cheng SH, Lau KM, Li CK, Chan NPH, Ip RKL, Cheng CK et al (2013) Minimal residual disease-based risk stratification in Chinese childhood acute lymphoblastic leukemia by flow cytometry and plasma DNA quantitative polymerase chain reaction. Plos One. 8(7):e69467

3. Schrappe M (2012) Minimal residual disease: optimal methods, timing, and clinical relevance for an individual patient. Hematology Am Soc Hematol Educ Program. 2012:137-142. https://doi.org/10.1182/asheducation-2012.1.137

4. Moorman A, Chilton L, Wilkinson J (2010) A population-based cytogenetic study of adults with acute lymphoblastic leukemia. Blood. 115:206-214

5. Kager L, Lion T, Attarbaschi A, Koeing M, Strehl S, Haas O (2007) Incidence and outcome of TCF3-PBX1-positive acute lymphoblastic leukemia in Austrian children. Haematologica. 92(11):1561-1564

6. Pieters R, Carroll W (2008) Biology and treatment of acute lymphoblastic leukemia. Pediatr. Clin. North. Am. 55(1):1-20

7. Swerdlow SH, Campo E, Harris NL, Jaffe ES, Pileri SA, Stein H, Thiele J et al (2008) In: Swerdlow S, Campo E, Harris N, Jaffe E, Pileri S, Stein H, Thiele J (eds) WHO classification of tumours of haematopoietic and lymphoid tissues. IARC Press, Lyon, France

8. Campbell $L$ (2006) Cytogenetic and FISH techniques in myeloid malignancies. Methods Mol Med. 125:13-28

9. Hastings R, Howell R, Betts D, Porter S, Haferlach C, Dastugue N, et al. Guidelines and quality assurance for acquired cytogenetics a common European framework for quality assessment for banded chromosome studies and molecular cytogenetic investigations of acquired abnormalities. European Cytogenetics Association Newsletter. 2013; No 13.

10. Borowitz M, Devidas M, Hunger S, Bowman W, Carroll A, Carroll W (2008) Clinical significance of minimal residual disease in childhood acute lymphoblastic leukemia and its relationship to other prognostic factors: a Children's Oncology Group study. Blood. 111(12):5477-5485

11. Campana D, and Pui C. Childhood acute lymphoblastic leukemia. In: Postgraduate haematology [Hoffbrand AV, Catovsky D, Tuddenham EGD and Green AR (eds.)], 6th Edition, Chapter 25; P: 448-462, Wiley-BlackWell, UK.

12. Matloub $Y$, Angiolillo A, Bostrom B, Hunger SP, Gaynon P, Carroll W et al (2006) Double delayed intensification (DDI) is equivalent to single DI (SDI) in children with National Cancer Institute (NCl) standard-risk acute lymphoblastic leukemia (SR-ALL) treated on Children's Cancer Group (CCG) clinical trial 1991 (CCG-1991). Blood 108(11):47A-48A Meeting abstract:146

13. Seibel NL, Steinherz PG, Sather HN, Nachman JB, Delaat C, Ettinger $L$ et al (2008) Early postinduction intensification therapy improves survival for children and adolescents with high-risk acute lymphoblastic leukemia: a report from the Children's Oncology Group. Blood 1:111(5):2548-2555

14. Schultz K, Pullen D, Sather H, Shuster J, Devidas M, Borowitz M et al (2007) Risk- and response-based classification of childhood B-precursor acute lymphoblastic leukemia: a combined analysis of prognostic markers from the Pediatric Oncology Group (POG) and Children's Cancer Group (CCG). Blood. 109(3):926-934

15. Siddaiahgar S, Awagbad S, Latha M (2015) Clinical, Immunophenotype and cytogenetic profile in children at tertiary health care centre in India. Muller J Med Sci Res 6:112-118

16. Rowe J (2010) Prognostic factors in adult acute lymphoblastic leukaemia. Br J Haematol 150:389-340

17. Pui C, Pei D, Campana D, Cheng C, Sandlund J, Bowman W et al (2014) A revised definition for the cure of childhood acute lymphoblastic leukemia. Leukemia 28:2336-2343

18. Borowitz M, Wood B, Devidas M, Loh M, Raetz E, Salzer W et al (2015) Prognostic significance of minimal residual disease in high-risk B-ALL: a report from Children's Oncology Group study AALL0232. Blood. 126(8):964-971

19. Rocha J, Xavier S, Souza M, Assumpção J, Murao M, de Oliveira B (2016) Current strategies for the detection of minimal residual disease in childhood acute lymphoblastic leukemia. Mediterr J Hematol Infect Dis 8(1): e2016024. https://doi.org/10.4084/MJHID.2016.024

20. Coustan-Smith E, Song G, Clark C, Key L, Liu P, Mehrpooya M et al (2011) New markers for minimal residual disease detection in acute lymphoblastic leukemia. Blood. 117(23):6267-6276

21. Al-Kzayer L, Sakashita K, Matsuda K, Al-Hadad S, Al-Jadiry M, Abed W et al (2012) Genetic evaluation of childhood acute lymphoblastic leukemia in Iraq using FTA cards. Pediatric Blood Cancer. 3(1):1-7

22. Jeha S, Coustan-Smith E, Pei D, Sandlund J, Rubnitz J, Howard S et al (2014) Impact of tyrosine kinase inhibitors on minimal residual disease and outcome in childhood Philadelphia chromosome-positive acute lymphoblastic leukemia. Cancer. 120:1514-1519

23. Terwilliger T, Abdul-Hay M (2017) Acute lymphoblastic leukemia: a comprehensive review and 2017 update. Blood Cancer J 7:e577-e589 
24. Möricke A, Lauten M, Beier R, Odenwald E, Stanulla M, Zimmermann M et al (2013) Prediction of outcome by early response in childhood acute lymphoblastic leukemia. Klin Padiatr. 225(Suppl. 1):S50-S56

25. Harvey R, Mullighan C, Wang X (2010) Identification of novel cluster groups in pediatric high-risk B-precursor acute lymphoblastic leukemia with gene expression profiling: correlation with genome-wide DNA copy number alterations, clinical characteristics, and outcome. Blood. 116(23):4874-4884

26. Cooper S, Brown P (2015) Treatment of pediatric acute lymphoblastic leukemia. Pediatr. Clin. North. Am 62(1):61-73

27. Juárez-Velázquez M, Salas-Labadía C, Reyes-León A, Navarrete-Meneses M, Fuentes-Pananá E, Pérez-Vera P. Genetic markers in the prognosis of childhood acute lymphoblastic leukemia. In: Clinical epidemiology of acute lymphoblastic leukemia - from the molecules to the clinic.2013; 3:193-235. https://doi.org/10.5772/54288.

28. Fielding A (2010) How I treat Philadelphia chromosome-positive acute lymphoblastic leukemia. Blood. 116(18):3409-3417

29. Shiozawa $Y$, Pedersen E, Taichman R (2010) GAS6/ Mer axis regulate the homing and survival of the E2A/PBX1-positive B-cell precursor acute lymphoblastic leukemia in the bone marrow niche. Experimental Hematology. 38:132-140

30. Pui C, Pei D, Raimondi S, Coustan-Smith E, Jeha S, Cheng C et al (2017) Clinical impact of minimal residual disease in children with different subtypes of acute lymphoblastic leukemia treated with response-adapted therapy. Leukemia. 31(2):333-339

31. Woo J, Alberti M, Tirado C (2014) Childhood B-acute lymphoblastic leukemia: a genetic update. Exp Hematol Oncol 3(16):1-14

32. Orbo N, Ryder L, Madsen H, Andersen M, Lausen B, Hasle H et al (2012) Identification of residual leukemic cells by flow cytometry in childhood Bcell precursor acute lymphoblastic leukemia: verification of leukemic state by flow-sorting and molecular/cytogenetic methods. Haematologica. 97: 137-141

33. Tamai H, Inokuchi K (2010) 11q23/MLL acute leukemia: update of clinical aspects. J Clin Exp Hematol. 50(2):91-98

34. Monika Bruggemann M, Raff T, Kneba M (2012) Has MRD monitoring superseded other prognostic factors in adult ALL? Blood. 120(23):4470-4481

35. Vora A, Goulden N, Wade R (2013) Treatment reduction for children and young adults with low-risk acute lymphoblastic leukaemia defined by minimal residual disease (UKALL 2003): A randomized controlled trial. Lancet Oncol. 14:199-209

36. Basso G, Veltroni M, Valsecchi M, Dworzak M, Ratei R, Silvestri D et al (2009) Risk of relapse of childhood acute lymphoblastic leukemia is predicted by flow cytometric measurement of residual disease on day 15 bone marrow. J Clin Oncol. 27(31):5168-5174

\section{Publisher's Note}

Springer Nature remains neutral with regard to jurisdictional claims in published maps and institutional affiliations.

\section{Submit your manuscript to a SpringerOpen ${ }^{\circ}$ journal and benefit from:}

- Convenient online submission

- Rigorous peer review

- Open access: articles freely available online

- High visibility within the field

- Retaining the copyright to your article

Submit your next manuscript at $\boldsymbol{\nabla}$ springeropen.com 